\title{
LA CLAUUSULA DE INDEMNIDAD POR RECLAMOS DE TERCEROS
}

\author{
THE INDEMNITY CLAUSE FOR THIRD PARTY CLAIMS
}

KAREN MUÑOZ VILLAGRA*

CARLOS PIZARRO WILSON**

\section{RESUMEN}

La cláusula de indemnidad por reclamos de terceros es frecuente en los contratos complejos. Su origen foráneo dificulta su comprensión, dado que puede alterar en mayor o menor medida el régimen indemnizatorio que rige entre las partes de un contrato. De ahí el interés en una vez delineado el régimen indemnizatorio contractual discutir la tipología de estas cláusulas y cómo descifrar sus elementos, así como los efectos que generan conforme la técnica con que hayan sido redactadas. Se determina la noción de las cláusulas de indemnidad, su tipología, sus elementos, su confrontación con el régimen indemnizatorio y sus efectos.

Palabras clave: Cláusula de indemnidad, Contratos complejos, Responsabilidad contractual, Indemnización de perjuicios, Extensión de la indemnización, Efectos legales.

\footnotetext{
*Abogada. Licenciada en Ciencias Jurídicas y Sociales, Universidad de Chile. Ayudante de cátedra de Derecho civil, Universidad de Chile, Santiago, Chile. Correo: kmunoz@ylmv.cl. ORCID: https:// orcid.org/ 0000-0000-0000-0000.

**Abogado, Profesor de Derecho civil, Universidad Diego Portales, y Universidad de Chile, Santiago, Chile. Doctor en derecho, Universidad Paris II, Panthéon-Assas. Correo: carlos.pizarro@ udp.cl. ORCID: https://orcid.org/0000-0002-9417-5797.

Una versión preliminar de este texto fue publicada en francés: MuÑoz, Karen; PIZArro, Carlos, "La clauses d'indemnité, régard du droit continental”, en Mélanges en l'honneur du professeur Michel Grimaldi. Liber amicorum, Defrénois-Lextenso, Paris, 2020, pp. 697-706.
}

Artículo recibido el 12 de noviembre de 2020 y aceptado para su publicación el 7 de agosto de 2021 . 


\section{ABSTRACT}

The indemnity clause is common in complex contracts. Its foreign origin makes it difficult to understand, since it can alter to a greater or lesser extent the compensation regime that governs between the parties to a contract. Hence the interest in once the contractual compensation regime has been outlined, discussing the typology of these clauses and how to decipher their elements, as well as the effects they generate according to the technique with which they have been drawn up.

Keywords: Indemnity clause, Complex contracts, Breach of contract, Contract damages, Extension of damages, Legal consequences.

\section{INTRODUCCIÓN}

La cláusula de indemnidad ha devenido en una cláusula de estilo en la contratación sofisticada en que intervienen actores complejos, en especial en los contratos de construcción y de servicios de larga duración, sobre todo aquella que cubre por reclamos de terceros. ${ }^{1} \mathrm{Su}$ definición y comprensión no es límpida y, por lo mismo, resulta necesario, como ocurre de manera frecuente con cláusulas foráneas que se importan del common law a los contratos locales, escudriñar, no sólo su noción, sino también su régimen convencional y legal, además de lo que refiere a su redacción e interpretación. ${ }^{2}$ Además, la doctrina no le ha prestado mayor atención salvo por excepción. ${ }^{3}$ No pocos problemas en la comprensión de la cláusula se han suscitado, lo que exige, de manera previa, considerar de manera somera la regulación o comprensión del remedio indemnizatorio en el derecho local,

\footnotetext{
${ }^{1}$ En general y sobre la tipología de cláusulas, CoRraL, Hernán, "Una aproximación a la recepción de las 'cláusulas de indemnidad por reclamaciones de terceros' en el derecho de contratos chileno", en Ramírez, G.; Varsi, E. (eds.), Congreso Internacional de Derecho Civil. Diálogo entre Disciplinas, Universidad de Lima - Instituto Pacífico, Lima, 2019, T. I, pp. 203-223.

${ }^{2}$ Una panorámica general y completa sobre este tipo de cláusulas en ScHOPF, Adrián "Las cláusulas de indemnidad en el derecho de contratos", en Elorriaga, F. (ed.), Estudios de Derecho Civil XV, Thomson Reuters, Santiago, 2020, pp. 685 y ss.

${ }^{3}$ CÁrdenas, Hugo; Reveco, Ricardo, Remedios contractuales. Cláusulas, acciones y otros mecanismos de tutela del crédito, Thomson Reuters, Santiago, 2018, p. 162 y ss.
} 
pues la referida cláusula incide de manera convencional en la exclusión o limitación de la indemnización de perjuicios. Acá se analiza la cláusula de indemnidad en el entendido que faculta al beneficiario a exigirle al deudor que le reembolse los gastos e indemnizaciones que haya debido pagar con ocasión de un evento previsto en el contrato y que ha originado un daño a un tercero que ha reclamado la respectiva indemnización al beneficiario de la indemnidad. Se analiza, entonces, la cláusula de indemnidad en su faceta de inmunidad de indemnizaciones reclamadas por terceros.

\section{EL DERECHO COMÚN DE LA INDEMNIZACIÓN DE PERJUICIOS POR INCUMPLIMIENTO CONTRACTUAL}

Sólo de manera general es necesario plantear los aspectos esenciales de la indemnización de perjuicios en cuanto remedio frente al incumplimiento contractual. Se justifica esta aproximación ligera por la incidencia de la cláusula de indemnidad en el régimen indemnizatorio que nos provee el Código Civil al alero de la doctrina y jurisprudencia. Sin perjuicio que acá se esbozarán problemas sustantivos que requieren un desarrollo más intenso, sólo nos conformaremos con delinear el régimen de la indemnización de perjuicios y sus principales debates en la actualidad. Propio a un modelo de derecho continental, el Código Civil chileno recoge la indemnización por incumplimiento del contrato en forma dispersa, sin ningún esfuerzo de sistematización, lo cual se mantiene incólume en el derecho civil chileno. De ahí que el régimen indemnizatorio en el ámbito contractual sea fruto del esfuerzo de la doctrina y jurisprudencia. ${ }^{4}$ Este puñado de reglas previstas en el Código Civil relativas a la indemnización de perjuicios, ha permitido en un esfuerzo persistente y paulatino para la construcción del régimen jurídico de la responsabilidad contractual, circunscrita ésta a la indemnización de perjuicios. Entre las reglas que deben considerarse en forma perentoria está, en primer lugar, el artículo 1545 del Código Civil que recoge la fuerza obligatoria del contrato y ante el quiebre de la palabra dada el acreedor puede, de acuerdo con el artículo 1489 del mismo Código,

\footnotetext{
${ }^{4}$ De la MAZA, Iñigo; VIDAL, Álvaro, Cuestiones de derecho de contratos. Formación, incumplimiento y remedios. Doctrina y jurisprudencia, Thomson Reuters, Santiago, 2019, p. 609 y ss.; CÁrdenas y ReVECO, cit. (n. 3), p. 373 y ss.
} 
tratándose de un contrato bilateral, invocar la acción de cumplimiento o resolutoria más la indemnización de perjuicios o, como ya se ha consolidado en nuestra jurisprudencia, la acción indemnizatoria de manera autónoma. ${ }^{5}$ La indemnización de los perjuicios ocasionados por el incumplimiento es consistente con la obligatoriedad del contrato al alcanzarse la satisfacción del acreedor aunque por una vía alternativa a la ejecución en naturaleza. Una vez infringido el acuerdo, la indemnización requiere incumplimiento, el que debe entenderse hoy como una desviación de lo acordado cualquiera sea su causa. Esta concepción neutra del incumplimiento se ha ido asentando en la doctrina local, constituyendo la base para configurar qué remedio contractual es procedente. ${ }^{6}$

En forma reiterada en la doctrina se ha afirmado que la indemnización de perjuicios exige culpa, lo que convoca la aplicación del artículo 1547 del Código Civil, en el cual se recoge la teoría de prestación de culpas para conforme la utilidad reportada fijar la diligencia exigida al deudor. Este artículo establece cuál es la diligencia que debe emplear el deudor para cumplir con su obligación, lo que permite determinar a qué se obliga el deudor, cuál es la prestación que debe ejecutar conforme los términos del contrato. Esto habilita a sostener, como primera premisa, que el régimen de responsabilidad contractual es, por regla general, por culpa, pues para determinar si existe incumplimiento debe aclararse si el deudor se apartó del modelo de conducta que le era exigible -buen padre de familia- y sólo en ese evento podrá calificarse su comportamiento como culpable en la hipótesis de los contratos bilaterales. De esta forma, puede afirmarse que la obligación que asume el deudor, en los términos del artículo 1547 del

\footnotetext{
${ }^{5}$ Corte Suprema, 31 de Octubre de 2012, Rol ํ3 3325-2012. Un análisis completo en LóPEz, Patricia, La autonomía de la indemnización de daños por incumplimiento de un contrato bilateral en el código civil chileno, LegalPublishing, Santiago, 2014; Pizarro, Carlos, "Por la autonomía de la acción indemnizatoria por incumplimiento contractual. Sentencia de la Corte de Apelaciones de Punta Arenas, 9 de Enero de 2007", Revista Chilena de Derecho Privado, 2007, Vol. 9, p. 151 y ss.; CÁrdenAs, Hugo, "Sobre la autononomía de la acción indemnizatoria. Reflexiones a propósito del caso 'Zorin con Cia. Siderúrgica Huachipato 2012"”, Revista de Derecho Escuela de Postgrado Universidad de Chile, 2014, $\mathrm{n}^{\mathrm{o}} 5$, p. 377 y ss.

${ }^{6}$ Sobre incumplimiento neutro: Morales, Antonio Manuel, "La noción unitaria de incumplimiento en la propuesta de modernización del Código Civill", en González, I.; García, C. (Coords.), Estudios sobre el incumplimiento y resolución, Aranzadi, Cizur Menor, 2014 p. 27 y ss; VIDAL, Álvaro, "La noción de incumplimiento esencial en el Código Civil", Revista de Derecho P. Universidad Católica de Valparaíso, 2009, nº 32, p. 495 y ss:; De La MaZa y VIDAL, cit. (n. 4), p. 246 y ss..
} 
Código Civil es una de medios o de diligencia, pero estableciéndose la carga de la prueba de la diligencia al deudor. ${ }^{7}$ Esto no es pacífico al sostenerse por una parte de la doctrina que es viable acoger la responsabilidad objetiva en el ámbito de la responsabilidad contractual desde que es posible calificar la obligación del deudor como una de resultado. ${ }^{8}$ La clasificación de las obligaciones como de medios y de resultado permite, entonces, precisar el deber de prestación del deudor. ${ }^{9} \mathrm{O}$ sea, por regla general se acepta que la indemnización de perjuicios exige una conducta culpable del deudor, lo que sólo por excepción se afirma puede variar si se trata de una obligación de resultado. Podemos convenir que el régimen indemnizatorio por regla general exige culpa.

No sólo se ha planteado como exigencia la culpa, sino también la mora, pero ésta de acuerdo con el artículo 1557 del Código Civil debe circunscribirse a los perjuicios moratorios, mas no aplica tratándose de la indemnización de otro tipo de daños que no sean por el retardo, llamados compensatorios. ${ }^{10}$

El acreedor para obtener la indemnización debe acreditar el daño cuya indemnización reclama. En este sentido el artículo 1556 del Código Civil establece que el incumplimiento puede originar daño emergente o lucro cesante, los cuales deben probarse por el demandante y acreedor que pretende la indemnización. A estos rubros de daños se ha agregado el daño moral para casos puntuales en que es posible determinar que ese daño era previsto a la época de celebrar el contrato, y en forma más reciente, la pérdida de la posibilidad.

En tercer término, el acreedor debe acreditar el vínculo causal entre la conducta culpable del deudor y los daños que reclama. Esto se deriva del artículo 1558 del Código Civil que reconoce la regla de previsibilidad en

\footnotetext{
${ }^{7}$ Pizarro, Carlos, "La culpa como elemento constitutivo del incumplimiento en las obligaciones de medio o de diligencia”, Revista de Derecho P. Universidad Católica de Valparaíso, 2008, Vol. 31, p. 255 y ss.

${ }^{8}$ Peñailillo, Daniel, "Responsabilidad contractual objetiva”, en Pizarro, C. (Coord.), Estudios de Derecho Civil IV. Jornadas Nacionales de Derecho Civil, LegalPublishing, Santiago, 2009, p. 331 y ss.

${ }^{9}$ De la Maza y Vidal, cit. (n. 4), p. 620.

${ }^{10}$ Sobre este debate, por todos: CONTARDO, Juan Ignacio, "Una interpretación restrictiva sobre los efectos de la constitución en mora del deudor según el Código Civil", Revista de Derecho P. Universidad Católica de Valparaíso, 2018, Vol. 43, pp. 77 y ss.
} 
materia de daños contractuales, limitándolos a aquellos previstos conforme la norma contractual, la cual está determinada por el proceso de negociación, tratativas preliminares, intercambio de información y el tenor del contrato. ${ }^{11}$ Esto permite delinear qué daños quedan dentro de la esfera de daños indemnizables. Aquí se configura el otro elemento necesario que permite establecer una causalidad material entre el incumplimiento y el daño, pero también un criterio de imputación jurídico, dado que no toda consecuencia del incumplimiento se indemniza, sino sólo aquellos que quedan dentro de la esfera de control del deudor atendida la norma contractual que se determina por el propósito práctico del contrato, excluyendo subjetividades de las partes.

Este régimen supletorio previsto en el Código Civil permite aseverar que el deudor puede excluir la responsabilidad acreditando que satisfizo su obligación, que hizo lo que correspondía conforme al contrato, lo que es coincidente con el artículo 1547 inciso $3^{\circ}$ del Código Civil y el artículo 1698 del mismo Código, pues al probar la diligencia está acreditando la extinción de la obligación mediante el pago, el cumplimiento de la obligación. En cuanto a los daños, deben ser acreditados por el acreedor y lo mismo en relación con el vínculo causal, conforme al artículo 1698 en relación con los artículos 1556 y 1558, todos del Código Civil.

Además, el deudor puede exonerarse de indemnizar los perjuicios que se le reclaman, ya sea porque acredita fuerza mayor o caso fortuito, hecho del mismo acreedor o mora creditoris, o si el daño ha sido ocasionado por un tercero del cual no le corresponde responder. En particular, la fuerza mayor erradica en todo caso la indemnización de perjuicios. En estos casos no existe razón para imputarle responsabilidad al deudor pues no ha causado los daños y, por ende, no resultan imputables jurídicamente conforme lo dispuesto en el artículo 1558 del Código Civil.

Estas reglas, tal como han sido expuestas, pueden modificarse por acuerdo de las partes, según disponen los artículos 1547 inciso final y 1558 inciso final. En el primero se indica "Todo lo cual, sin embargo, se entiende sin perjuicio de las disposiciones especiales de las leyes, y de las

\footnotetext{
${ }^{11}$ Corral, Hernán, Contratos y daños por incumplimiento, Abeledo Perrot - LegalPublishing, Santiago, 2010, p. 176 y ss.; CoRral, Hernán, "La regla de la previsibilidad de los daños contractuales: un ejemplo de la influencia de la doctrina de Pothier en las tradiciones del derecho civil continental y de common law", Revista de Derecho Universidad Católica del Norte, 2009, nº 2, p. 132 y ss.
} 
estipulaciones expresas de las partes". Y, por su parte, el segundo precepto, señala "Las estipulaciones de los contratantes podrán modificar estas reglas".

En consecuencia, el Código Civil admite modificar la diligencia que debe emplear el deudor, la carga de la prueba, si responde o no por caso fortuito y determinar de qué daños responde y en qué forma, a través de estipulaciones expresas que alteren este régimen común de indemnización de perjuicios por incumplimiento contractual. La libertad contractual habilita a los contratantes a modelar en forma bastante libre las reglas relativas a la indemnización de perjuicios.

Este modelo, así descrito en forma más que sintética es lo que se altera o se pretende alterar con la cláusula de indemnidad.

\section{TIPOLOGÍA DE CLÁUSULAS DE INDEMNIDAD}

La cláusula de indemnidad puede definirse como un acuerdo en que una de las partes se obliga a asumir cualquier responsabilidad, pérdida, gasto o daño sufrido por la otra parte, beneficiaria de la cláusula, derivados de actos o condiciones ahí descritas, por lo que asume el pago de un perjuicio resultante del reclamo o demanda de un tercero, aunque no se haya ocasionado. ${ }^{12}$ La parte que se obliga a pagar los daños o pérdidas es el "deudor de la indemnidad" y la parte en cuyo favor se pacta, "beneficiario de la indemnidad". ${ }^{13}$ A veces también se utilizan las expresiones "Parte Indemnizada" y "Parte Indemnizante". Cárdenas y Reveco afirman que "el otorgante, se obliga ante la otra, que será la beneficiaria, a "mantenerla indemne" frente a la materialización de algún evento previsto en el contrato, asumiendo las consecuencias patrimoniales que de ello se deriven, en principio mediante un pago". ${ }^{14}$ En términos estrictos no sólo contempla

${ }^{12}$ Es esta la hipótesis frecuente en los contratos de indemnidad, sin perjuicio que existan otras posibilidades, CORRAL, cit. (n. 1), p. 206; SCHOPF, cit. (n. 2), p. 686.

${ }^{13}$ CAstro, Marcela, "Cláusulas de indemnidad: Aproximación a su problemática en el derecho colombiano”, en Aramburo, M. (Coord.), Responsabilidad Civil, Derecho de Seguros y Filosofia del Derecho. Homenaje al Profesor Javier Tamayo Jaramillo, Ed. Dike, Medellín, 2011, T. I, p. 585.

${ }^{14}$ CÁrdenas y Reveco, cit. (n. 3), p. 162. Los autores la analizan desde la perspectiva de la adquisición de una empresam, lo que los induce a plantear la relación con las declaraciones y garantías que mediante la cláusula de indemnidad quedarían cubiertas. Enseguida dan ejemplos de otros contratos en que son 
asumir la indemnización a que se condena, lo que tendría su origen en la ejecución del contrato en que consta la cláusula de indemnidad, sino también gastos que se hayan originado durante la secuela del juicio que puede dar lugar a la condena al pago de los perjuicios. Las cláusulas de indemnidad refieren al reembolso de los gastos y la reparación del daño causado por el evento que gatilla la aplicación de la cláusula. Estas cláusulas, podrían alterar las reglas de la responsabilidad civil, transfiriendo el deber de indemnizar a una parte, que en principio no está obligada a cubrir esos daños, pues no los ha ocasionado por una conducta que le sea imputable. Así opera una genuina transferencia de riesgos por eventos previstos a la época de celebrarse el contrato, aunque inciertos en relación con su ocurrencia. Es decir, puede que no haya incumplido el contrato, que los daños cuya indemnización se reclama y que le genera gastos al beneficiario de la cláusula no los haya causado. Al igual que toda cláusula que altera el régimen supletorio previsto en el Código Civil y siguiendo una larga tradición hermenéutica, para los efectos que tienen estas cláusulas, se ha señalado por la doctrina y jurisprudencia extranjera que la interpretación de su alcance debe hacerse de forma restrictiva, por lo cual el intérprete debe estarse a lo expresamente pactado en ella. ${ }^{15}$ Lo que es consistente con el modelo del Código civil chileno, el cual como dijimos, si bien admite alteración en sus reglas, ese cambio debe ser expreso y claro, en caso contrario se vuelve a la regla general, el derecho supletorio. Por lo mismo, se requiere un análisis específico del lenguaje de las expresiones contractuales utilizadas en la indemnidad en cada caso. ${ }^{16}$

Conforme lo dispuesto en el artículo 1547 inciso $3^{\circ}$ del Código Civil y el inciso final del artículo 1558 del mismo Código, las partes, echando mano a la libertad contractual al celebrar estas cláusulas alteran los elementos del derecho dispositivo de la responsabilidad contractual. Estas cláusulas, en todo caso, no son uniformes o unívocas, pues pueden incidir en cuestiones ajenas a la indemnización de perjuicios, por ejemplo reembolso de gastos con ocasión de situaciones que no refieren a un incumplimiento contractual

\footnotetext{
habituales, tales como de agencia y de asociación.

${ }^{15}$ CAStro, cit. (n. 13), p. 602; SCHOPF, cit. (n. 2), p. 698, en particular sobre la culpa o negligencia de la parte beneficiaria de indemnidad que analiza como un problema de interpretación.

${ }^{16}$ BROwn, Richard D.; ForTIN, Mara E., "An introduction to interpretation of express contractual indemnity provisions in construction contracts under California and Nevada Law", McGeorge L. Rev, 2001, Vol. $32, \mathrm{n}^{\circ} 4$, p. 1019 y ss.
} 
o que ni siquiera fueron causadas por el deudor de la indemnidad o, en cambio, pueden limitarse a agravar ciertos aspectos de la indemnización de perjuicios, pero circunscribiéndose al marco regulatorio de los daños y perjuicios consecutivos al incumplimiento del contrato. La sola calificación de la cláusula como una de indemnidad, no fija de forma automática sus efectos, ya que podemos encontrarnos con distintos tipos de cláusulas de indemnidad, de ahí la necesidad de estructurar una cierta tipología.

Es usual en el caso de traducción o importación de cláusulas desde la familia del common law que se generen estos problemas de interpretación. Al alterarse el derecho dispositivo o pretenderse alterarlo sin claridad acerca de lo que significa la introducción de una cláusula de esta naturaleza genera el riesgo de la ambigüedad y severas dificultades de interpretación.

No existe una visión unívoca de las cláusulas de indemnidad, sino que distintos tipos que se recogen en la práctica contractual.

Así, por ejemplo, la Corte Suprema de California, EE.UU., para efectos de interpretar las cláusulas de indemnidad, ha distinguido tres tipos de acuerdos de indemnidad.

El primer tipo, cubre los supuestos de negligencia del acreedor de la indemnidad, es decir, si el acreedor de la indemnidad es culpable y es el único causante del daño. Este es el tipo de acuerdo menos favorable para el deudor y más favorable para el beneficiario, ya que incluye un espectro más amplio de indemnización de daños para el acreedor de la indemnidad, y abarca supuestos en que hay una ausencia de negligencia por parte del deudor. ${ }^{17}$ Se altera acá en forma radical el sistema de responsabilidad de derecho común, al responder el deudor incluso por la culpa del acreedor, sin que haya incumplimiento, ni menos culpa de su parte en los perjuicios que reclama un tercero.

En el segundo tipo de acuerdos, el deudor debe indemnizar los supuestos en que haya sido negligente y haya producido el daño al tercero, y además, debe indemnizar los supuestos en que haya negligencia pasiva concurrente del acreedor de la indemnidad, aunque no cubre los supuestos de negligencia activa del acreedor. Estas cláusulas abarcan, en consecuencia, el supuesto típico en que el mandante se ve arrastrado a un juicio por daños ocasionados por el incumplimiento de su contratista, bajo el supuesto de la responsabilidad contractual por el hecho de otro. Se trata de un resguardo

${ }^{17}$ Brown y Fortin, cit. (n. 16), p. 1023. 
para el mandante ante posibles incumplimientos dañinos de sus contratistas frente a terceros. Si bien éstos pueden demandar al contratista, es usual que busquen la indemnización en el mandante si tiene mayor envergadura económica, por lo que a través de la cláusula el mandante queda al abrigo del pago, el cual deberá desembolsarse en último término por el contratista. Puede esta cláusula de indemnidad considerar además que el obligado a contribuir a la deuda indemnizatoria sea el contratista, aunque exista también culpa del mandante en concomitancia con la de su contratista. Es decir, el fenómeno de culpas compartidas que ocasionan el daño exigiría que de igual manera el total de la deuda sea asumida por el contratista, a pesar de la culpa del mandante. Estos acuerdos son llamados por las cortes como "indemnización general". ${ }^{18}$ El matiz es claro, no se responde por la culpa exclusiva del beneficiario de la cláusula, pero si en caso de concurrencia de causas tanto del beneficiario como del deudor.

Finalmente, en el tercer tipo de cláusulas de indemnidad, las partes acuerdan que el deudor de la indemnidad solo indemnizará sus actos $\mathrm{u}$ omisiones que causen total o parcialmente el daño, pero no indemnizará los actos u omisiones atribuibles a la negligencia del acreedor, independientemente de si dichos actos u omisiones constituyen negligencia activa o pasiva. ${ }^{19} \mathrm{La}$ indemnización se limita a los actos $\mathrm{u}$ omisiones causados directamente por el deudor de la indemnidad. Bajo esto acuerdo, el deudor no proporcionará indemnización al contratista general o al desarrollador $\mathrm{u}$ otros por negligencia de otras entidades o personas. Se reconduce el asunto acá a una cláusula que contempla en forma clara la contribución a la deuda en el lenguaje de las obligaciones solidarias. El contratista sólo asume los daños que causa y si esos le son reprochados a

\footnotetext{
${ }^{18}$ Brown y Fortin, cit. (n. 16), p. 1023. La distinción entre negligencia activa y pasiva es compleja. Un acreedor de la indemnidad que participa de alguna manera en la conducta o el fracaso para actuar que se determina como causa del daño y que va más allá del mero incumplimiento tipificado por la ley es activamente negligente y por lo tanto, no tiene derecho a indemnización en virtud de este tipo de acuerdo de indemnidad. Por el contrario, un acreedor de la indemnidad que infringe su deber de cuidado impuesto por la ley, pero que no participa con una negligencia activa que es sindicada como la causante del daño de un tercero, es calificada como pasivamente negligente y sujeto a indemnización bajo este tipo de acuerdos. La distinción entre negligencia activa y pasiva no está reconocida por el derecho chileno, sino que se alude a un estándar de conducta abstracto, cuya infracción constituye negligencia, sin distinguir el carácter activo o pasivo, siendo la negligencia más bien un concepto unitario.
}

${ }^{19}$ Brown y Fortin, cit. (n. 16), p. 1024. 
su mandante, por cierto, deberá asumirlos, pues la causa de los perjuicios fue su propia conducta, lo que lo transforma en quien debe contribuir en definitiva a la deuda.

Se observa la dificultad para asignar significado a las cláusulas de indemnidad, pues no sólo se partan en gran medida del derecho supletorio indemnizatorio, sino que sobre todo no resultan homogéneas, abarcando situaciones en que un sujeto asume el pago de indemnización de daños que ni siquiera causó con su conducta, pero que se relacionan con el encargo que se le hizo.

La interpretación de los enunciados lingüísticos de los que se vale la cláusula de indemnidad es esencial para calificar frente a qué tipo de acuerdo nos encontramos, y de esta forma, determinar los efectos de la cláusula. La libertad contractual reina, pero es necesario averiguar a qué se obligó el deudor de la indemnidad en específico: eso es resorte de la técnica contractual y cómo las cláusulas de indemnidad quedan plasmadas en el acuerdo.

\section{LA TÉCNICA CONTRACTUAL EN LAS CLÁUSULAS DE INDEMNI- $D A D$}

Como en la mayoría de las cláusulas, los problemas se suscitan a partir su redacción e interpretación. En si basta la utilización de la voz "indemnidad" en la cláusula para entender si nos encontramos frente a una genuina cláusula de indemnidad o a una simple iteración del régimen de responsabilidad civil contractual. ${ }^{20}$

La interpretación de los enunciados lingüísticos de los que se vale la cláusula de indemnidad es esencial para calificar frente a qué tipo de acuerdo nos encontramos, y de esta forma, determinar los efectos de la cláusula. El solo calificativo como cláusula de indemnidad no atribuye de forma automática que lo sea y que acarree sus efectos.

Calificar se entiende como la determinación de la naturaleza de un vínculo de derecho con el objetivo de enmarcarlo en una de las categorías jurídicas existentes y dotarlo de un régimen de reglas que le resulta aplicable. Se trata de asignar un nombre legal a algo, en este caso una cláusula, que

${ }^{20}$ Corral, cit. (n. 1), p. 210. 
permita lograr un orden, un régimen que le sea aplicable, el cual deriva, precisamente, de la denominación que le atribuyamos. La necesidad de calificar es ineluctable, incluso esencial, sólo eso permite otorgar reglas a una determinada categoría aceptada en el ordenamiento jurídico y dotarla de un contenido compartido que habilite al correcto entendimiento entre los actores jurídicos. Y en la operación de calificación la voluntad de las partes tiene un rol estelar, pues ellas saben que al calificar tal o cual institución de una manera precisa, otorgándole una denominación están, en base al lenguaje jurídico, atribuyéndole un sentido, pero también una estructura y un régimen normativo. Sin duda la voluntad o el acuerdo de las partes es impotente para excluir una calificación determinada por la ley, de tal manera que no podemos aceptar que por convención o declaración unilateral aquello que la ley califica de una forma, sea modificado. Pero más allá del ámbito imperativo de las reglas, en las convenciones a partir de la libertad contractual, las partes pueden establecer estipulaciones que consagren derechos y obligaciones que no contraríen los límites usuales, las buenas costumbres, el orden público y la ley. Es lo que ocurre con las reglas dispuestas en los artículos 1547 y 1558 del Código Civil.

Si bien este tipo de cláusulas no están reguladas en el ordenamiento jurídico civil chileno, se entiende que en virtud de la libertad contractual serían lícitas. Sin embargo, estas cláusulas deben satisfacer determinadas condiciones y una estructura para atribuírseles la calificación de cláusulas de indemnidad y eficacia a la luz del derecho local de impronta continental.

Algunos problemas ha suscitado la sola utilización de la voz "indemne", en que una de las partes, comúnmente el beneficiario de la indemnidad, busca aprovecharse de este tipo de acuerdos, pues las cláusulas del contrato han utilizado este adjetivo. Para aclarar cuáles son efectos de las hipótesis cubiertas por las cláusulas, debemos despejar que entendemos por el término "indemne". El concepto de "indemne" no es extraño en nuestra legislación, sino que ha sido reconocido por el Código Civil en diversas disposiciones. De esta forma aparece en el inciso final del artículo 1555, que se refiere a las alternativas que tiene el acreedor frente al incumplimiento de una obligación de no hacer, que prescribe que "el acreedor quedará de todos modos indemne". A su vez, el artículo 1268, que se refiere a la acción reivindicatoria que puede ejercer el heredero sobre las cosas reivindicables que hayan pasado a terceros, conservando el derecho para que los poseedores de buena o mala fe de la herencia que la ocuparon le completen lo que no haya obtenido de 
los terceros, prescribiendo que "le deje enteramente indemne" al heredero. Finalmente, el artículo 1792-21 señala que el crédito de participación en los gananciales es puro y simple y se pagará en dinero, en el caso que se causare grave perjuicio al cónyuge deudor o los hijos comunes podrá el juez conceder plazo de hasta un año para el pago del crédito, debiendo asegurar el deudor o un tercero "que el cónyuge acreedor quedará de todos modos indemne".

El sentido que se le atribuye a la voz "indemne", es el de dejar al acreedor o heredero en la misma situación que si no hubiese acaecido el hecho que da origen a la indemnización de perjuicios o pago del crédito que se adeuda. Es decir, se le atribuye el sentido de reparación integral, sin que implique una situación de responsabilidad agravada del deudor, debiendo responder de hechos que no le incumban causalmente. No es más que la justicia correctiva, que coloca al deudor en situación de reparar los daños ocasionados y así restablecer el equilibrio roto con la conducta culpable en el incumplimiento de sus obligaciones, restableciendo el estado de cosas anterior, corrigiendo la transgresión del deber primario de causar daño y cumpliendo el deber secundario de reparar el daño causado.

Esta conclusión es importante, pues la simple mención al término "indemne", no puede tener como consecuencia la configuración de la cláusula de indemnidad, constituyendo una garantía a todo evento. Para determinar los efectos, debemos investigar otros elementos de la cláusula, en especial, los eventos desencadenantes, que desencadenan la aplicación de la indemnidad. Recordemos que el acuerdo debe prever ojalá con la mayor precisión cuáles son las hipótesis que desencadenan la obligación de indemnidad. Se debe señalar que ellos son la generación de daños o pérdidas provenientes de reclamos de terceros en conexión con las actividades realizadas por la parte deudora de la indemnidad. Los terceros deben particularizarse y pueden comprender, entre otros, trabajadores, organismos públicos y aún extraños que sufren un daño. ${ }^{21}$

Si se busca establecer una responsabilidad objetiva u otra más gravosa, por garantía, debe señalarse en términos explícitos, como lo exigen los artículos 1547 y 1558 del Código Civil. La voluntad debe ser clara. Debe señalarse que el deudor de la indemnidad responderá por el sólo hecho de haber causado el daño sin necesidad de culpa o dolo de su parte. O más intensa, el deudor responderá de todo daño causado por su conducta, actos

${ }^{21}$ CAstro, cit. (n. 13), p. 595. 
u omisiones, sin necesidad de probar culpa y aún por todo caso fortuito o fuerza mayor. Es así como deben distribuirse los riesgos en el contrato, si se quisiere, a lo que se suma, un cierto equilibrio necesario, pues si se va a responder de esa forma, deben tomarse los resguardos conducentes a la posibilidad de ocurrencia.

Además, las Cortes en EE.UU., lugar de origen de este tipo de cláusulas que han sido trasplantadas al derecho continental, al interpretar estas disposiciones contractuales, lo hacen en forma restrictiva, en especial en el caso de los acuerdos de indemnidad del primer tipo, en que el beneficiario de la indemnización busca obtener una indemnización por sus propios actos negligentes. ${ }^{22}$ Por lo tanto, no existiendo un lenguaje contractual claro y expreso que obligue al deudor a responder a todo evento, incluso de los actos negligentes del beneficiario de la indemnidad, se debe entender que la cláusula de indemnidad sólo cubre los actos u omisiones negligentes emanados de su propia parte o de quienes están a su cargo. Es decir, se deben interpretar como el tercer tipo de acuerdo de indemnidad analizado.

\section{LOS ELEMENTOS DE LA CLÁUSULA DE INDEMNIDAD}

Para que una cláusula de indemnidad cumpla su función, aparte de aparecer en forma expresa y clara en el contrato, debe contener, al menos, menciones claras y detalladas sobre: i) su naturaleza de cláusula de indemnidad; ii) el deudor y el beneficiario de la indemnidad; iii) las contingencias que cubre; iv) los eventos desencadenantes; v) el alcance de la indemnidad, es decir, si el daño o pérdida se cubre en su totalidad mediante reembolso del valor pagado al tercero reclamante o si se acuerda un límite monetario a la indemnidad; y vi) cómo se cumple en concreto la obligación de defender y amparar al beneficiario, y si ella incluye los costos legales correspondientes, como honorarios de abogados. ${ }^{23}$ Los elementos que se mencionan acá son bastante obvios, pues inciden en los sujetos o partes del acuerdo de indemnidad, que ésta debe contemplar en qué casos procede, y mientras mejor se detallen, menos problemas habrá y la forma en que debe satisfacerse, tanto en lo temporal como en la cuantía, dado que

\footnotetext{
${ }^{22}$ Brown y Fortin, cit. (n. 16), p. 1026.

${ }^{23}$ Corral, cit. (n. 1), p. 208 y ss., Castro, cit. (n. 13), p. 604 y ss.
} 
puede considerarse una indemnidad asociada a una cláusula de limitación de la indemnidad que se cubre.

Aparte, es usual que se contemple un procedimiento para hacerla efectiva. La cláusula debe expresar las condiciones que debe satisfacer el beneficiario para tener derecho a hacerla efectiva, en particular los deberes de notificación oportuna, colaboración y mitigación del daño. Esto involucra aspectos formales, pero también sustantivos. Por un lado, de qué manera se desencadena la puesta en práctica de la cláusula, a través de una notificación escrita de qué manera y la misma conducta del beneficiario debe ser conforme la buena fe, lo que conduce a que la oriente a evitar el agravamiento de lo que le corresponde pagar al deudor de la indemnidad. Además, el beneficiario tiene la carga de probar la ocurrencia del evento para poder beneficiarse del acuerdo de indemnidad. ${ }^{24}$

En los contratos de construcción, el acuerdo de indemnidad se orienta por lo general a que el constructor asegure al propietario el pago de cualquier pérdida por concepto de la responsabilidad que pueda surgir para éste por daños a terceros, ya sea a la propiedad o a las personas, surgidos de las actividades del constructor en la ejecución de sus obligaciones contractuales. Puede existir una cláusula de este tipo en los acuerdos suscritos entre el contratista y sus subcontratistas para mantener indemne al primero por daños que el mismo deba pagar al contratante -dueño de la obra y tercero en este caso- causados por hechos de los subcontratistas. ${ }^{25}$

Una típica cláusula de indemnidad contiene la obligación de una de las partes de asumir los costos que se prevean en dicha cláusula, generalmente generados por el desarrollo de la actividad objeto del contrato. Así, una cláusula de indemnidad podría suponer la existencia de la obligación de una de las partes de asumir el pago de los costos que pudieran generarse por el reclamo de un tercero e, incluso, asumir el costo de la asesoría legal necesaria para la defensa contra dicho reclamo; ello en busca de mantener indemne el patrimonio del beneficiario del pacto.

En ese sentido, las cláusulas de indemnidad cumplen la función de prevenir y asignar los riesgos que pudieran generarse en la ejecución de un contrato; siendo una garantía para mantener indemne el patrimonio del beneficiario, de forma tal que la actividad de la otra parte no signifique una

\footnotetext{
${ }^{24}$ CAStro, cit. (n. 13), pp. 604-605.

${ }^{25}$ Ibídem, p. 587.
} 
afectación a dicho patrimonio.

Las estipulaciones de las partes en torno a la indemnidad las vinculan exclusivamente a ellas y no pueden oponerse a los terceros accionantes o reclamantes. Es decir, ante un hecho que desencadene la indemnidad, los derechos de los terceros deberán atenderse conforme las reglas de la responsabilidad civil, y la cláusula tendrá el efecto de distribuir de manera interna entre las partes que suscribieron el pacto de indemnidad, las cargas y pérdidas correspondientes. ${ }^{26}$ No es más que una vulgar aplicación del efecto relativo de los contratos. Los terceros que reclaman los daños ocasionados al beneficiario de la indemnidad no pueden verse afectados por un acuerdo en el que no participaron. Por lo mismo, es usual el establecimiento de la repetición o una acción de reembolso a favor del beneficiario de la indemnidad, en el caso de que sea demandado y deba indemnizar a un tercero, o desembolse dinero producto del daño, dirigiéndola en contra del deudor de la indemnidad.

Podemos observar que la pluralidad de hipótesis de cláusulas de indemnidad dificultan su comprensión, lo que deja al intérprete en la necesidad de averiguar cuál tipo de indemnidad está recogida en la cláusula específica de qué se trata.

VI. LAS PARTICULARIDADES DE LAS CLÁUSULAS DE INDEMNIDAD FRENTE AL REGIMEN COMÚN DE RESPONSABILIDAD CIVIL CONTRACTUAL

De lo dicho hasta ahora, las cláusulas de indemnidad pueden alterar cualquiera de los elementos de la responsabilidad civil contractual. En este sentido, podemos señalar que las alteraciones se verifican respecto al elemento de imputación -la culpa-, si hay una iteración del régimen de responsabilidad por culpa o un compromiso con la responsabilidad objetiva, el alcance de los daños indemnizables, la causalidad - pues se puede prescindir por completo de ésta-y por último que la indemnidad se traduzca en un régimen de garantía, asumiendo el deudor la fuerza mayor o la culpa del acreedor. Ahí se responde a todo evento.

Una primera aproximación es enterder la cláusula de indemnidad solamente cubre los reclamos o cobros formulados por terceros que tengan su

${ }^{26}$ CAstro, cit. (n. 13), p. 594. 
causa en su propia culpa o dolo, sujetándose a la comprensión tradicional de la indemnización de perjuicios por incumplimiento contractual. Conforme a las normas generales de responsabilidad, lo más usual es que los terceros demanden al acreedor, o en el caso de un contrato de construcción, al dueño de la obra, aún por hechos causados por el contratista, en virtud de la regla del artículo 35 de la Ley de Concesiones, que determina como sujeto pasivo en la indemnización de los daños causados en la ejecución de la obra al Concesionario. Así, una cláusula de indemnidad podría suponer la existencia de la obligación de una de las partes de asumir el pago de los costos que pudieran generarse por el reclamo de un tercero e, incluso, asumir el costo de la asesoría legal necesaria para la defensa contra dicho reclamo; ello en busca de mantener indemne el patrimonio del beneficiario del pacto. Las estipulaciones de las partes en torno a la indemnidad las vinculan exclusivamente a ellas y no pueden oponerse a los terceros accionantes o reclamantes. Es decir, ante un hecho que desencadene la indemnidad, los derechos de los terceros deberán atenderse conforme con las reglas de la responsabilidad civil, y la cláusula tendrá el efecto de distribuir de manera interna entre las partes que suscribieron el pacto de indemnidad, las cargas y pérdidas correspondientes. ${ }^{27}$ Habrá derecho a la repetición o una acción de reembolso a favor del beneficiario de la indemnidad, en el caso de que sea demandado y deba indemnizar a un tercero, o desembolse dinero producto del daño, dirigiéndola en contra del deudor de la indemnidad. Y esta cláusula se transforma en un derecho de reembolso por los daños que haya debido responder el acreedor de la indemnidad frente a terceros, pudiendo esgrimirse en contra del deudor contra los gastos e indemnización de perjuicios desembolsado frente a terceros. Es decir, no altera las normas generales de la responsabilidad contractual, sino que simplemente establece una acción de reembolso en el supuesto que el daño se haya ocasionado a terceros. Esta sería la fórmula más beneficiosa para el deudor de la indemnidad, que solo responde por su culpa o dolo.

Respecto a la culpa, una cláusula de indemnidad puede recoger pura y simplemente un régimen objetivo de responsabilidad contractual, en cuyo caso el deudor responderá aunque no exista culpa. De cara al beneficiario si se han generado daños a terceros, aún sin culpa, y resulte afectado el beneficiario, el deudor deberá responder. Es decir, todo daño, sea causado

${ }^{27}$ CAstro, cit. (n. 13), p. 594. 
con o sin culpa, que tenga un origen causal en la actuación u omisión del deudor, deberá ser indemnizado por el deudor de la indemnidad. En relación a las reglas de los artículos 1547 y 1558 del Código Civil, este tipo de pactos serían válidos, ya que se modifica la regla de la culpa en materia de responsabilidad civil, prescindiéndose de ella, trasladando el riesgo del acaecimiento del daño del acreedor al deudor en el caso que no exista culpa, siempre que exista causalidad entre la acción u omisión del deudor. Este tipo de cláusula es lícita y rige la libertad contractual.

Este tipo de cláusulas puede ir un poco más allá, además de asumir un compromiso con la responsabilidad objetiva, el acreedor puede obligarse a responder del caso fortuito o fuerza mayor, transformándose la cláusula de indemnidad en una responsabilidad por garantía. En este supuesto, se estaría modificando el presupuesto de la causalidad, ya que existiría responsabilidad sin causalidad, en el caso que los daños indemnizables sean fruto de un caso fortuito o fuerza mayor. El deudor de la indemnidad se obliga a indemnizar o reembolsar gastos de eventos que fueron ocasionados por un hecho externo a su actuar.

Distinto es si el deudor de la indemnidad puede responder por culpa exclusiva del acreedor, lo que altera en forma sustancial el régimen de derecho común. ${ }^{28}$ La eficacia de los pactos con los cuales se pretende variar las reglas generales de la responsabilidad contractual ha sido discutida. Se cuestiona hasta qué punto puede la libertad contractual alterar los principios de la responsabilidad civil y en qué aspectos existen consideraciones de orden público que impiden a las partes establecer estipulaciones que se ajustan mejor a sus intereses económicos. Estas cláusulas han estado bajo cuestionamiento en ciertos casos, especialmente cuando el pacto dispone que el beneficiario de la indemnidad puede acudir a ella aun cuando el daño sea imputable a su propia negligencia o haya contribuido a la producción del perjuicio. ${ }^{29}$ Para evitar los abusos en la contratación y con el propósito de incentivar las conductas diligentes a la hora de ejecutar las obligaciones contractuales, actualmente, 43 de los Estados de EE.UU. han promulgado leyes anti-indemnidad en contratos de construcción, no para proscribir estos

\footnotetext{
${ }^{28}$ Sobre este asunto, $\mathrm{S}_{\mathrm{CHOPF}}$, cit. (n. 2), p. 698. Este autor opta por una solución que deja el problema en una mera cuestión de interpretación contractual, por lo que si es posaible constatar que la deudora de indemnidad asumió la culpa o dolo de la benefic iaria sería válida y produciría efectos.

${ }^{29}$ CAstro, cit. (n. 13), p. 590.
} 
pactos, sino para declararlos ineficaces cuando pretenden beneficiar a quien con su negligencia produjo o contribuyó a la producción del daño. ${ }^{30}$

Esta ineficacia de este tipo de pactos de indemnidad, que obligan al deudor a responder de los hechos del beneficiario tiene sentido en nuestro derecho civil, pues equivaldría a una condonación del dolo futuro, por lo cual este tipo de cláusulas adolecerían objeto ilícito si buscan beneficiar a quien causa el daño con dolo o culpa grave. ${ }^{31}$ Por lo tanto, aunque las partes hayan pactado este tipo de cláusulas de indemnidad, que equivalen al primer tipo señalado, no serían válidos a la luz de nuestro sistema jurídico.

\section{CONCLUSIÓN}

Podemos concluir que la cláusula de indemnidad es válida a la luz del ordenamiento jurídico chileno, no sólo en virtud de la libertad contractual, sino sobre todo porque los artículos 1547 inc. final y 1558, ambos del Código Civil, permiten alterar las reglas supletorias relativas a la indemnización de los perjuicios. De otra parte, estas cláusulas suelen tener una fisonomía variada lo que impide reconocerlas en una manifestación homogénea. La pluralidad de tipos de cláusulas de indemnidad incide en qué medida se agravará la posición del deudor, el cual puede quedar limitado a responder por sus propios actos o incluso por los del beneficiario, aunque no haya participado causalmente a daños a terceros o no tenga participación en la realización de los riesgos que asumió en el contrato. De ahí el interés en descifrar con claridad de qué tipo de cláusula de indemnidad se trata y así definir a qué se obligó el deudor. Esto no impide sostener que al menos una cláusula radical de indemnidad que admita el reembolso o el pago íntegro de indemnizaciones o costos que haya asumido o deba asumir el beneficiario no pueden estar conectados con una conducta dolosa de éste, lo que debería proscribirse conforme la regla que prohíbe la condonación de dolo futuro.

\footnotetext{
${ }^{30}$ Ibídem, p. 591.

${ }^{31}$ En este sentido CÁrdenas y Reveco, cit. (n. 3), p. 165.
} 


\section{BIBLIOGRAFÍA CITADA}

\section{a) Doctrina}

Brown, Richard D.; ForTin, Mara E., "An introduction to interpretation of express contractual indemnity provisions in construction contracts under California and Nevada Law", McGeorge L. Rev., 2001, Vol. 32, n 4.

CÁrdenas, Hugo; Reveco, Ricardo, Remedios contractuales. Cláusulas, acciones y otros mecanismos de tutela del crédito, Thomson Reuters, Santiago, 2018.

CÁRDENAS, Hugo, "Sobre la autononomía de la acción indemnizatoria. Reflexiones a propósito del caso 'Zorin con Cia. Siderúrgica Huachipato 2012'", Revista de Derecho Escuela de Postgrado Universidad de Chile, 2014, n 5.

CAstro, Marcela, "Cláusulas de indemnidad:Aproximación a su problemática en el derecho colombiano", en Aramburo, M. (Coord.), Responsabilidad Civil, Derecho de Seguros y Filosofía del Derecho. Homenaje al Profesor Javier Tamayo Jaramillo, Ed. Dike, Medellín, 2011, T. I.

Contardo, Juan Ignacio, "Una interpretación restrictiva sobre los efectos de la constitución en mora del deudor según el Código Civil", Revista de Derecho P. Universidad Católica de Valparaíso, 2018, Vol. 43.

Corral, Hernán, Contratos y daños por incumnplimiento, Abeledo Perrot LegalPublishing, Santiago, 2010.

Corral, Hernán, "La regla de la previsibilidad de los daños contractuales: un ejemplo de la influencia de la doctrina de Pothier en las tradiciones del derecho civil continental y de common law", Revista de Derecho Universidad Católica del Norte, $2009, n^{\circ} 2$.

Corral, Hernán, "Una aproximación a la recepción de las 'cláusulas de indemnidad por reclamaciones de terceros' en el derecho de contratos chileno", en Ramírez, G.; Varsi, E. (eds.), Congreso Internacional de Derecho Civil. Diálogo entre Disciplinas, Universidad de Lima - Instituto Pacífico, Lima, 2019, T. I, pp. 203-223.

De la Maza, Iñigo; Vidal, Álvaro, Cuestiones de derecho de contratos. Formación, incumplimiento y remedios. Doctrina y jurisprudencia, Thomson Reuters, Santiago, 2019.

López, Patricia, La autonomía de la indemnización de daños por incumplimiento de un contrato bilateral en el código civil chileno, LegalPublishing, Santiago, 2014.

Morales, Antonio Manuel, "La noción unitaria de incumplimiento en la propuesta de modernización del Código Civil”, en GonzÁlez, I.; GArcía, C. (Coords.), Estudios sobre el incumplimiento y resolución, Aranzadi, Cizur Menor, 2014.

PeÑAIlillo, Daniel, "Responsabilidad contractual objetiva”, en Pizarro, C. 
(Coord.), Estudios de Derecho Civil IV. Jornadas Nacionales de Derecho Civil, LegalPublishing, Santiago, 2009.

Pizarro, Carlos, "Por la autonomía de la acción indemnizatoria por incumplimiento contractual. Sentencia de la Corte de Apelaciones de Punta Arenas, 9 de Enero de 2007”, Revista Chilena de Derecho Privado, 2007, Vol. 9.

Pizarro, Carlos. "La culpa como elemento constitutivo del incumplimiento en las obligaciones de medio o de diligencia", Revista de Derecho P. Universidad Católica de Valparaíso, 2008, Vol. 31.

Schopf, Adrián, "Las cláusulas de indemnidad en el derecho de contratos", en Elorriaga, F. (ed.), Estudios de Derecho Civil XV, Thomson Reuters, Santiago, 2020, p. 685 ss.

VIDAL, Álvaro, "La noción de incumplimiento esencial en el Código Civil" en Revista de Derecho P. Universidad Católica de Valparaíso, 2009, Vol. 32,

b) Jurisprudencia

Corte Suprema, 31 de Octubre de 2012, Rol N 3325-2012. 